\title{
INSTALAÇÕES GEOGRÁFICAS - PENSANDO A AVALIAÇÃO CONSTRUTIVA PARA SE TRABALHAR A GEOGRAFIA NA SALA DE AULA
}

\author{
Emerson Ribeiro ${ }^{1}$
}

\begin{abstract}
Resumo: $O$ texto aqui explorado especifica uma abordagem diferente sobre a prática pedagógica e avaliação. Sabemos dos riscos empreendidos no diferente, mas é necessário quando pretendemos realizar algo novo. A prática inserida tem a pretensão de mostrar como o ensino de Geografia no ensino básico e na universidade pode encontrar também na Arte sua relação de ensino aprendizagem. O Processo consiste em trabalhar o conteúdo com abordagem lúdica, é aplicado um conteúdo teórico para uma manifestação prática - na forma de instalações, professor e aluno em conjunto constroem a instalação. O exemplo por nós escolhido é apresentado na forma de instalações na Universidade Regional do Cariri no município de Crato/CE, com alunos do VI semestre.
\end{abstract}

Palavras Chaves: Geografia; Instalações; Avaliação Construtiva.

\section{Installations geographic - thinking assessment for construction work if the geography in the classroom}

\begin{abstract}
The text specifies here explored a different approach on pedagogical practice and assessment. We know the risks undertaken in different, but it is necessary when we want to do something new. The practice inserted intend to show how the teaching of geography in elementary school and university can also find their relationship in art education learning. The Process is to work with content playful approach, a theoretical content is applied to a practical manifestation in the form of facilities, teachers and students together construct the facility. The example chosen by us is presented in the form of facilities at the University Regional Cariri at Crato / CE, with students from VI semester.
\end{abstract}

Key Words: Geography; installations; Constructive Evaluation.

\section{EXÓRDIO}

"O fim da arte é quase divino: ressuscitar, se faz história; criar, se faz poesia." Victor Hugo

A elocução exercida no texto passeia pela arte e a geografia, faz se necessária quando se quer dissolver o que tá posto, mesmo correndo os riscos que o diferente apresenta aos olhos do tradicional, mas é preciso romper sem perder o rigor acadêmico, necessário para apresentar a metodologia com as instalações geográficas. Entendemos a instalação como uma forma para se expressar a construção de um determinado conhecimento trabalhado com signos e símbolos. $\mathrm{O}$ termo instalação passa a ser incorporado ao vocabulário das artes visuais na década de 1960,

\footnotetext{
${ }^{1}$ Prof. Dr. Emerson Ribeiro -Departamento de Geociências da Universidade Regional do Cariri-URCA - Rua Cel. Antônio Luis, 1161 - $63.100-000$ Pimenta - Crato/CE Fone: (88) 3102.1212. E-mail: emerprof@hotmail.com
} 
designando ambiente construído em espaços de galerias e museus, prioritariamente, para mais tarde ganhar as praças, parques e as ruas públicas.

As instalações geográficas se constroem a partir de um conteúdo que no nosso caso em questão para o exercício didático se traduz na "Formação da População Brasileira" dando subsídios para a formação de novos professores para o ensino de geografia escolar.

O encontro com novas práticas pedagógicas que levem a desvendar outra metodologia no fazer pedagógico para a formação de professores, pode nos levar ao encontro de um novo processo de ensino aprendizagem, baseado no teórico/ prático sem esquecermo-nos da manifestação criativa. No que diz respeito ao processo de ensino e aprendizagem é necessário compreender a natureza do processo metodológico. Nesse sentido coloco como necessidade a apresentação de uma avaliação alternativa aos modelos já existentes, uma avaliação por instalações que requer uma construção do conhecimento geográfico a partir do uso da arte, sustentada pela pesquisa para a superação do cotidiano escolar.

Ressaltamos que a prática realizada tem como finalidade a formação de novos professores, apresentar algo que os incomode, que os tire do chão, suspendendo o cotidiano e a mesmice metodológica que acanha tantas escolas e salas de aulas, pois de nada nos adianta o discurso se a nossa prática não tem relação com a ação pedagógica, essa é nossa proposta, a transformação da sala de aula.

Apostamos nos parágrafos que seguem para uma contribuição ao processo de avaliação, apresentaremos a seguir no subtítulo "o alicerce" algumas considerações sobre a avaliação e os tipos de avaliação presentes no processo de ensino aprendizagem, as considerações a avaliação de longe segue um compêndio, mas faremos as prerrogativas em cima da discussão da avaliação formativa, para mais a frente colocar a nossa proposta.

\section{O ALICERCE}

Em relação à avaliação, existe uma variedade de designações, conceitos que normalmente são utilizadas quando os seus autores querem referir a algum tipo de avaliação como: "avaliação autentica Telles, avaliação contextualizada Berlak, avaliação formadora Nunziati, regulação controlada dos processos de aprendizagem Perrenoud, avaliação educativa Gipps" (FERNANDES, 2006). 
As avaliações citadas se referem a uma avaliação para orientar, para melhorar as aprendizagens, mais contextualizada a um papel em que o aluno tem a desempenhar.

Num certo sentido poderemos dizer que todas são alternativas a uma avaliação que, genericamente, se caracteriza por dar mais ênfase aos processos de classificação, de selecção e de certificação, aos resultados obtidos pelos alunos, à utilização sumativa dos resultados dos testes ou à prestação de contas (FERNANDES, 2006, pg.25)

De certa forma, podemos analisar as características dessas avaliações e suas mutações e perceber que elas são variações, como aponta Fernandes, mais ou menos elaboradas de uma avaliação formativa inspirada em concepções cognitivistas, construtivistas e/ou socioculturais da aprendizagem.

Afinal como podemos medir? O que é medir?

Ideia essa preconizada para medir mudanças comportamentais, aprendizagem, mas também para quantificar resultados, ou méritos, encontra-se apoiada no positivismo. Ela visa a comprovar um rendimento do aluno com base nos objetivos (de conteúdo ou comportamental) essa quantificação é sistemática, ela se determina nas mudanças de comportamento do aluno e em que medida essas mudanças ocorrem, a avaliação e reduzida à medida e seu resultado se separa do processo de ensino (CALDEIRA, 2000, pg.23).

Segundo Hadji (2001, pg.27), "medir significa atribuir um número a um acontecimento ou a um objeto, de acordo com uma regra logicamente aceitável". Esse autor nos traz que a ideia de medir o desempenho dos alunos esta enraizada fortemente na mente dos professores, mas também na dos alunos, essa concepção reside na suposta "norma" das medidas adotadas pelas instituições e nos parâmetros nas "formas" utilizados pelos professores para atribuir uma nota, um número, uma letra aos trabalhos dos alunos.

Uma medida é objetiva no sentido de que, uma vez definida a unidade, deve-se ter sempre a mesma medida do mesmo fenômeno. Certamente, um erro é sempre possível, devido às imperfeições da instrumentação, pois ele resulta então das condições de operacionalização dos instrumentos. Ele provém da operação de medida. Por essa razão, pode ser calculado e, portanto, neutralizado (HADJI, 2001, pg.27).

Portanto, reduzir a avaliação à medida implica aceitar a credibilidade da avaliação como instrumento de medida e desconsiderar que o resultado da avaliação não pode ter a subjetividade do avaliador, interferindo nos valores finais.

(...) registraremos aqui o fato de que hoje se sabe que a avaliação não é uma medida pelo simples fato de que o avaliador não é um instrumento, e porque o 
que é avaliado não é um objeto no sentido imediato do termo. Todos os professores avaliadores deveriam, portanto, ter compreendido definitivamente que a "nota verdadeira" quase não tem sentido (HADJI, 2001, pg. 34).

Em se tratando da avaliação formativa, a mesma

(...) sustenta que sua função principal é a de contribuir para uma boa regulação da atividade de ensino. (...) uma avaliação não precisa conformar-se a nenhum padrão metodológico para ser formativa (HADJl, 2001, pg. 19).

Não podemos deixar de apontar outra lógica- a formativa- para o processo avaliativo, que se preocupam com o processo de apropriação do conhecimento pelo aluno, os diferentes caminhos que percorrem mediados pela intervenção ativa do professor, a fim de promover a organização e regulação das aprendizagens, para que o fracasso não ocorra, inserindo o aluno no processo educativo.

Nesse tipo de avaliação, a lógica e sua concepção se apóia em verificar se o aluno no final dos estudos ou semestre e ano letivo, se o mesmo adquiriu conhecimento.

Para esse processo de avaliação, Azzi aponta:

A avaliação que acontece ao final nos dá uma dimensão do significado e da relevância do trabalho realizado. Difundida nos meios educacionais com a denominação de somativa, é sempre associada à idéia de classificação, aprovação e reprovação. Tal associação tem sentido e não é errada em uma proposta que tenha esses objetivos. Numa proposta que vise à inclusão do aluno, a avaliação final necessita ser, redimensionada, sem perder seu caráter de seriedade e rigor (AZZI, 2001, pg. 19).

Diante desse processo de entender a avaliação e a sua importância, recorremos à outra matriz que é avaliação de cunho qualitativo, que propõe um processo de ultrapassagem da avaliação quantitativa que detém as premissas epistemológicas vigentes na atualidade.

A avaliação qualitativa pretende ultrapassar a avaliação quantitativa, sem dispensar esta. Entende que no espaço educativo os processos são mais relevantes que os produtos, não fazendo jus à realidade, se reduzida apenas às manifestações empiricamente mensuráveis. Estas são mais fáceis de manipular metodologicamente, porque a tradição científica sempre privilegiou o tratamento mensurado da realidade, avançando, por vezes, de maneira incisiva em algumas disciplinas sociais, como a economia e psicologia. Todavia, não se pode transferir a limitação metodológica a pretensa redução do real. Este é mais complexo e abrangente do que sua face empírica. A avaliação qualitativa gostaria de chegar até à face qualitativa da realidade, ou pelo menos de se aproximar dela (DEMO, 2004, pg. 156). 
Podemos perceber que a avaliação qualitativa apresenta-se como um modelo em transição por ter como centralidade a compreensão dos processos da aprendizagem e de ensino, o que produz uma ruptura.

Que para Libâneo o conceito de avaliação da aprendizagem apresenta-se como;

(...) o componente do processo de ensino que visa, através da verificação e qualificação dos resultados obtidos, determinar a correspondência destes com os objetivos propostos e, daí, orientar a tomada de decisões em relação às atividades didáticas (LIBÂNEO,2004, pg. 196).

Essas configurações têm relação com o processo histórico de desenvolvimento das técnicas e da ciência, passando pelas conquistas territoriais, tendo a Igreja com os (Jesuítas) e os Reinos como precursores, até a revolução industrial onde os Estados à frente das grandes corporações que se estabeleciam no território, encontravam-se um modelo de trabalho baseado na quantidade, mas também no medo, na punição de perder o emprego, que passou a envolver todo o processo de produção, correlacionado com mão de obra como força de mercado e este em tomada de decisões, sempre quantificando, mas sempre com viés produtivo.

Para a superação no processo de ensino aprendizagem nos que diz respeito ao processo de avaliação, propomos uma avaliação pelo professor pesquisador intitulada como alternativa as "avaliações" acima descritas; por uma avaliação de instalações em geografia, uma Avaliação Construtiva. Antes, de enfocar a avaliação por instalações, vamos compreender o termo usado por muitos pesquisadores como "avaliação alternativa".

A expressão avaliação alternativa, ao longo da década de 90 do século XX, e inicio do XXI tem sido usada constantemente na literatura como se fosse uma muleta para segurar todo e qualquer tipo de processo de avaliação anunciado a regular e a melhorar a aprendizagens.

Para Fernandes, é focado nos processos, mas sem ignorar os produtos, participado, transparente, que não seja essencialmente baseado em testes de papel e lápis e integrado nos processos de ensino e de aprendizagem.

E ainda nos coloca Fernandes que, "a designação avaliação alternativa esteja associada a um conjunto de características e práticas próprias da avaliação formativa de inspiração cognitivista e construtivista, nem sempre é claro do que se está realmente a falar quando é utilizada" (FERNANDES, 2006, pg. 24), pois, essa designação pode significar passagens diferentes para diversos autores.

Devido às concepções teóricas e filosóficas de vários autores, até o momento apresentado, temos ainda, que a avaliação da aprendizagem recebe diversos conceitos, termos e interpretações. 
Entre esses diversos processos de avaliação podemos concluir que ao longo do tempo, diversas matrizes e concepções teóricas conforme o tempo histórico e os interesses da classe dominantes são as que seguem a frente das políticas públicas são as que programam na educação, no seu tempo, a concepção desejável.

Na realidade o que sobra a nossas escolas e alunos é a avaliação enquanto classificação, medida, juízo de valores, cobrança, disciplina, etc. É a punição observada entre professores e alunos para fornecer dados estatísticos de aprovação, para o banco mundial, para uma sociedade insaciável marcada pela competição engendrada no neoliberalismo e no capitalismo de mercado.

A avaliação construtiva termo designado pelo professor pesquisador retrata o processo de conhecimento que o aluno irá percorrer até o produto final, esse produto se realimenta diante do processo criativo, num ciclo que para a criança e o jovem são de extrema importância, pois levam os alunos a desenvolver experiências para enfrentar o cotidiano.

A avaliação por instalações geográficas exigem do aluno conteúdo, pesquisa, imaginação e criatividade, entre outras competências possíveis de serem alcançada com relação à atividade proposta pelo professor. Esses elementos ocorrem devido ao processo de combinação e de complexidade, em particular do acumulo de experiência. Como já relatado no texto em que Vygotsky (2004) aponta a diversidade e a experiência de uma pessoa como elementos importantes para a criação.

Quando abordamos o conteúdo da geografia na sala de aula, e em seguida pedimos aos alunos que de posse do objeto (o qual se realizará a instalação), esse caminho a ser percorrido pelo aluno, aprofundando o tema da pesquisa, dialogando com a sala, exigindo das complexidades da linguagem a sua passagem para a escrita, reinventando as suas experiências criativas, buscando junto aos seus pais, alunos, etc., encontrando no final o ato de imaginar e construir o seu objeto, que dele resulta numa apresentação para um dado público, esses dados, essas informações, esses símbolos indubitavelmente se traduzira em um processo de conhecimento, resultando em aprendizagem.

A metodologia por instalações geográficas tendo como processo de avaliação a construção do saber, não deixando de lado as outras formas de avaliação, atingem a realidade ou pelo menos se aproxima dela, levando ao professor a tomar novas decisões e rever os seus resultados podendo dessa maneira corrigi-los se necessário. 


\section{A OBRA}

Nesse segmento vamos abordar uma prática pedagógica realizada na Universidade Regional do Cariri - URCA com os alunos da disciplina de Estágio Supervisionado. Conteúdo programático: “A Formação da População Brasileira" proposta essa relacionada no currículo para os alunos do ensino fundamental II.

Esse tema do ponto de vista da didática poderia ser abordada de várias maneiras, entre elas dentro do ensino tradicional, porém, como a nossa proposta é de superar as avaliações tradicionais $^{2}$ (não que devemos dispensá-la no todo), contudo é preciso uma boa dose de criação e imaginação para materializar a teoria em prática, contextualizando-a em conhecimento e não na memorização.

Para encontrar essa prática, essa didática, temos que usar da representação das categorias da geografia, deslocando-a do livro didático para outra forma de expressão da linguagem. Para tanto, foram criadas oficinas (em que os alunos ministraram o conteúdo de maneira criativa sugerida pelo professor) em sala de aula para a abordagem do tema em questão, para chegarmos até as instalações. Exemplificando a didática temos:

1- Abordagem por estimulação sobre o que conhecem sobre o assunto retratado, no caso a formação da população brasileira.

2- Conteúdos teóricos e delimitação do processo histórico-geográfico e uso de mapas.

3- Ensaios e erros, apresentação de imagens (mapas).

4- Estabelecer relações entre fatos e conceitos.

5- Questionamentos a respeito do tema, competências e habilidades apuradas.

6- O professor delega a tarefa de pesquisar sobre a formação da população brasileira no território.

7- Aula ministrada pelos alunos (que aborde uma estratégia criativa) nas oficinas e debatidas pelos colegas em sala.

8- Depois de ministradas as aulas pelos alunos e o conceito sobre a formação da população brasileira (brancos, índios e negros) estiver sedimentada, explicada, (como ocorreu esse processo desde sua colonização com a invasão dos portugueses massacrando os indígenas

\footnotetext{
${ }^{2}$ Entendemos por a avaliação tradicional quando se mede quantidade de conteúdos que o aluno "aprendeu", realizado por um teste, trabalho, prova etc. Esse instrumento de avaliação não leva em consideração o percurso que o aluno percorreu, mas, apenas um determinado momento, passado esse momento o que sobra é muito pouco, cai no esquecimento, pois não houve um processo de conhecimento e sim uma memorização do conteúdo. Isso significa que o foco está apenas no conteúdo e, não, no desenvolvimento por completo, visando às competências e habilidades dos alunos. Apostamos que o ideal para os alunos, é que eles sejam mais criativos e inventivos e não presos apenas ao livro didático, ou os conteúdos explicado apenas pelo professor, por isso, defendemos a avaliação construtiva baseada nas instalações geográficas.
} 
e catequizando, passando pela escravidão e a imigração formando uma miscigenação do povo) assim, realizada pela tomada de conhecimento sobre o objeto em questão. Os alunos constroem um texto para serem apreciados em discussão em sala, e nesse texto eles apontam o material que será usado e a simbologia relacionada para a efetivação da avaliação.

9- Avaliação na forma de instalações geográficas.

10- Retorno a sala de aula para as manifestações de aprendizagem e ensino apreendidas. E texto de retorno.

Neste momento, a da avaliação, que as instalações devem se manifestar, a criação e o criador se encontram no espaço, pois exige do aluno além da aprendizagem a criatividade que perpassa as estruturas mentais, porque exige projeto, projeção mental, força de criação, conhecimento do conteúdo que irá construir durante todo o processo de criação, repetimos, relação por contrastes. Nesse exemplo os objetos a serem utilizados para representar o conteúdo proposto foram:

$\checkmark$ Madeiras medindo 1 metro de comprimento (para a construção de uma mesa).

$\checkmark$ Malha losangular (tela de galinheiro)

$\checkmark$ Pregos, martelo, serra, furadeira, cola quente, fita adesiva, tinta e barbantes.

$\checkmark$ Bonecas, essas despedaçadas, em parte dos membros

$\checkmark$ Palitos de churrascos, esses para espetar nas bonecas e colar as imagens.

$\checkmark$ Imagens representando a formação do povo brasileiro, e outras simbologias.

$\checkmark$ Barbantes, Cartolinas com frases sobre a formação do povo brasileiro:

$\checkmark$ Painel confeccionado pelos alunos sobre o tema.

$\checkmark$ E uma grande dose de criatividade por parte dos alunos e professor.

Nessa instalação o modelo de mesa com malha losangular e boneca despedaçadas foi proposta pelo professor, porém, essa metodologia também aborda as sugestões e discussões junto aos alunos, depende do ambiente e do conteúdo a serem exemplificados para se chegar ao modelo de instalação. 


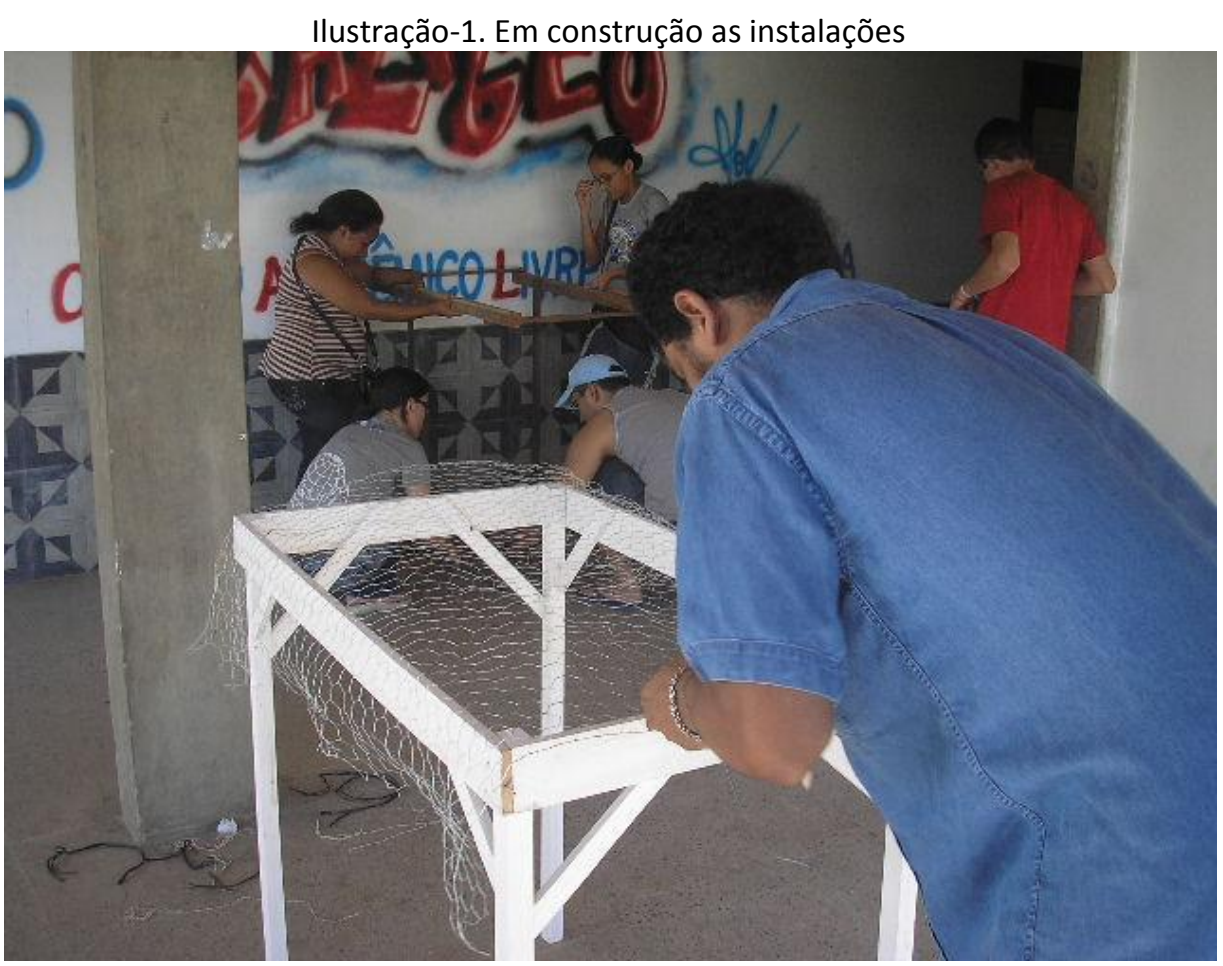

Fonte: Ribeiro, Emerson. Nov/2011.

Nessa construção avaliativa os alunos vão se deparar com um problema, como representar o que foi estudado? Os conceitos chaves da geografia são o lugar/território e a paisagem, não podemos deixar de expor que outros conceitos que abrangem essa aula apareceram durante as oficinas, como: ocupação, migração e seus movimentos, nação, sociedade, teoria de Malthus, teoria Reformista, demografia, etc., entre outras abordadas para essa manifestação do ensino aprendizagem.

Essa avaliação construtiva pode ser realizada em grupo de no máximo três pessoas (sugestão, para não dispersar os integrantes), que irá envolver atitudes, compromisso, formas de lidar com o processo avaliativo, pesquisa, criação e discussão envolvendo o grupo (colegas de classe). A família também passa a ser consultada, devido ao objeto (no nosso caso a construção de uma mesa) e em alguns casos se envolvem no conteúdo abordado. Liderança é observada pelo professor na busca pelo conhecimento, distribuição das tarefas e materiais a serem arranjados, etc. 


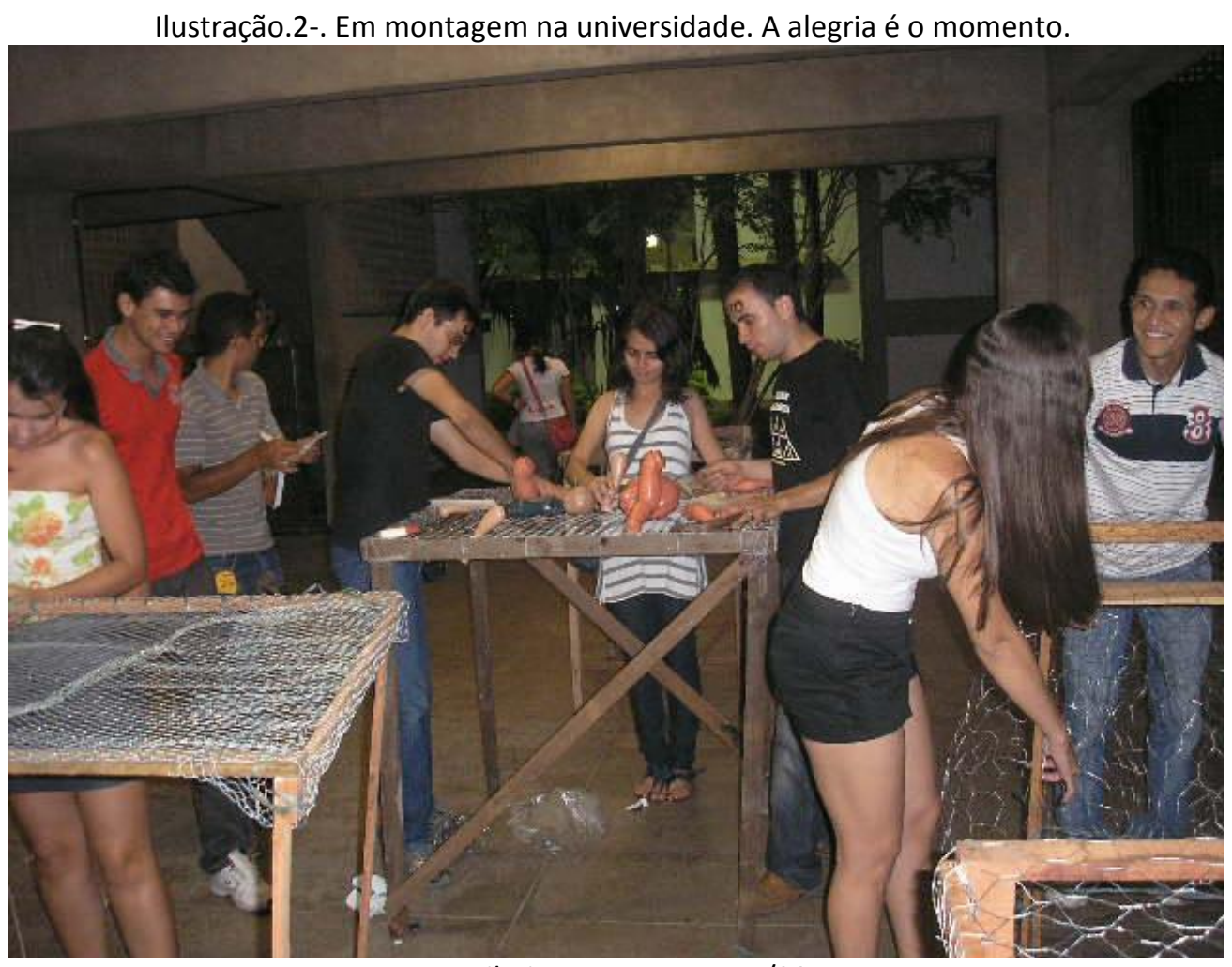

Fonte: Ribeiro, Emerson. Nov/2011.

Ilustração. 3-. A "Formação do Povo Brasileiro", representada em instalação.

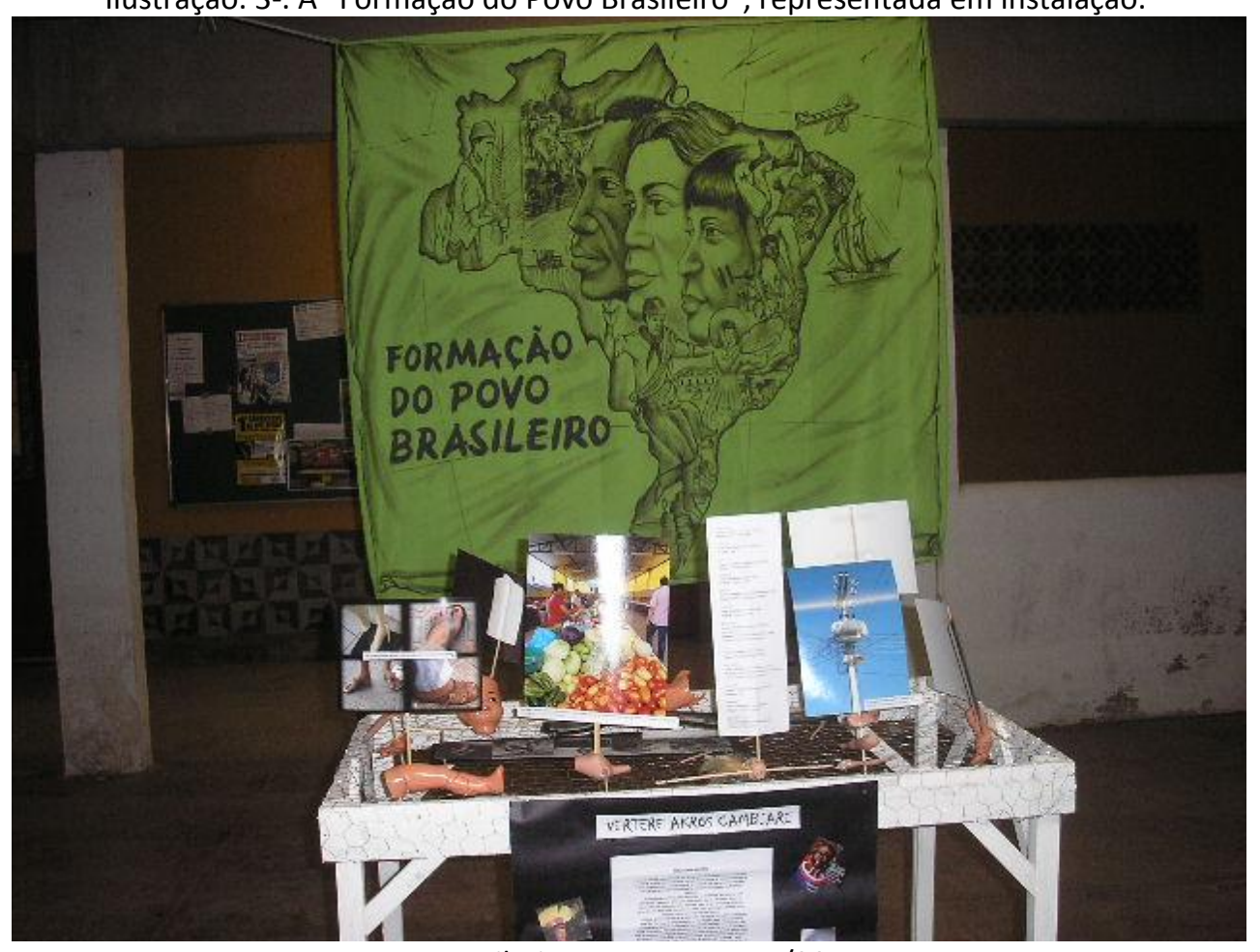

Fonte: Ribeiro, Emerson. Nov/2011. 
Em sala de aula as discussões são pertinentes aos objetos a serem colocados para a representação da população brasileira nas instalações e para o nome do evento; depois de diversas sugestões chegamos ao um título do evento "VERTERE AKROS CAMBIERE" que significa "Revirar (latim) ao extremo (em grego) para mudar (latim)".

Como já abordamos acima os alunos redigem um texto que explique os materiais abordados e a pesquisa realizada, e depois da avaliação exposta eles refazem o texto, abordarei abaixo parte de um relatório de uma aluna:

\section{"VERTERE AKROS CAMBIERE em formação da população brasileira.}

Repulsa espanto, surpresa, entusiasmo e indiferença. Foram muitos os sentimentos percebidos nas expressões do público que assistiu à experiência da mudança proposta e alertada por meio do movimento intitulado Vertere Akros cambiere organizado pelo professor Emerson Ribeiro e que sugestivamente significa Revirar ao extremo para mudar.

A intenção foi de propor o incentivo à prática da criatividade na universidade e na educação de modo geral, bem como a visualização dessa possibilidade $e$ necessidade, já que a educação atual é tão carente da atividade criativa, do novo, da inovação. Além disso, propôs vivenciarmos tal atividade para nos tornarmos aptos quando no exercício do magistério repassarmos esse estímulo à criação.

Nesse sentido foi de fundamental contribuição para a nossa formação docente, visto ter possibilitado analisar a importância da desconstrução e construção no processo ensino-aprendizagem, e perceber que fugir a essa linearidade e buscar a complexidade e a abordagem holística simbólica do conhecimento é bastante representativo e não tão difícil como pareceu inicialmente.

Enfim nos possibilitou perceber a aplicabilidade, apesar dos obstáculos a serem superados, dessa prática nas escolas, onde o aluno terá oportunidade de construir seu próprio conhecimento a partir da sua realidade de forma prazerosa e com integração entre os mesmos.

Apesar de apresentar dificuldades no início tentei atender a proposta de representar simbolicamente a formação da população brasileira, expondo sobre a mesa fotografias de um prato de sopa representando a mistura de gostos, de um pilão simbolizando a miscigenação das técnicas e ainda de um mosaico $e$ uma colcha de retalhos propondo a representação da diversidade e a união dos povos, culturas e hábitos constituintes de nossa população ${ }^{3}$.

É de extrema importância a pesquisa feita pelos alunos, para que possa representar na forma de instalação o conteúdo abordado. Todo o processo de ensino aprendizagem, passando pela avaliação construtiva até a apresentação requer um diálogo final que nos remeta aos erros e acertos por parte dos alunos e professor, pois ficam evidentes na apresentação as falas dos conteúdos abordados, quando eles são abordados por outros alunos, funcionários, etc. da universidade/escola, que participam dessa interação, desse movimento, num ato de aprendizado.

\footnotetext{
${ }^{3}$ Texto de Maria Cynara G. de Alencar, aluna do VI semestre, da URCA. No texto em questão foi mantida a grafia original, e o (grifo é nosso).
} 


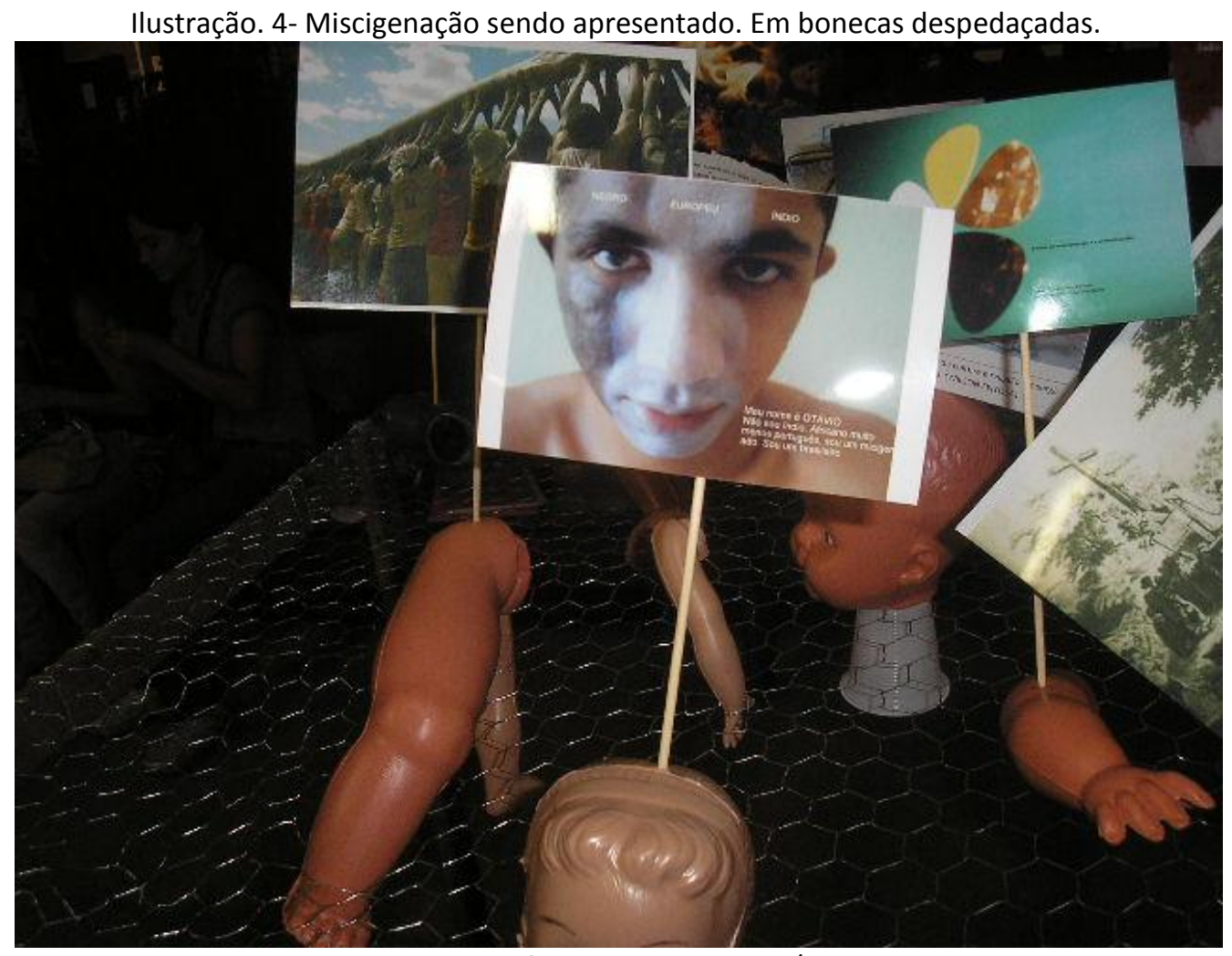

Fonte: Ribeiro, Emerson. Nov/2

Em outro texto e ilustração de um aluno da graduação (Paulo Bento) abordando a formação do povo brasileiro, relata:

Quando falamos de formação, vem logo a idéia de criação ou de nascimento, porém quando se trata de algo tão complexo como uma civilização ou sociedade que devemos levar em consideração, muitos fatores que possibilitam analisar os motivos desta suposta formação. Uma revelação que nos aproprie do que se formou, como se formou, e de que origem tem essa formação. As verdadeiras intenções não só das suas formações, mas de quem as formou, não esquecendo que em alguns casos as formações não passaram de deformações organizadas.

(...) Nossa deformação formou uma nação de homens sem chão, apertado na espacialidade entre os não lugares e lugar nenhum, vivendo um presente invisível, um passado sem glória, contudo, montado num cavalo de tróia. Sendo assim todos os nossos passos devem ser modificados, devemos andar com os nossos próprios pés, sem muleta alguma, sem tropeçar-nos próprios passos, e procurar em nós mesmos o que eles procuraram...

(...) Foi essa mesclagente composta de alma de índios, de negros, de mulatos, que fez crescer esse país. Ao longo da costa brasileira se encontraram duas visões de mundo completamente opostas: a "selvageria" dos homens brancos e a "civilização", dos Índios. Concepções diferentes de mundo, da vida, da morte, do amor, se chocaram.

A simbologia que usarei na formação e apreciação ao povo brasileiro será os Pés. Os pés foram e sempre será o símbolo da própria invasão dos brancos portugueses, das fugas nas matas de índios e negros 
e da audácia, e resiguinação persistente de avançar contra as espadas, baionetas e escudos policiais, pois só existe um jeito de chegar até a porta é indo...

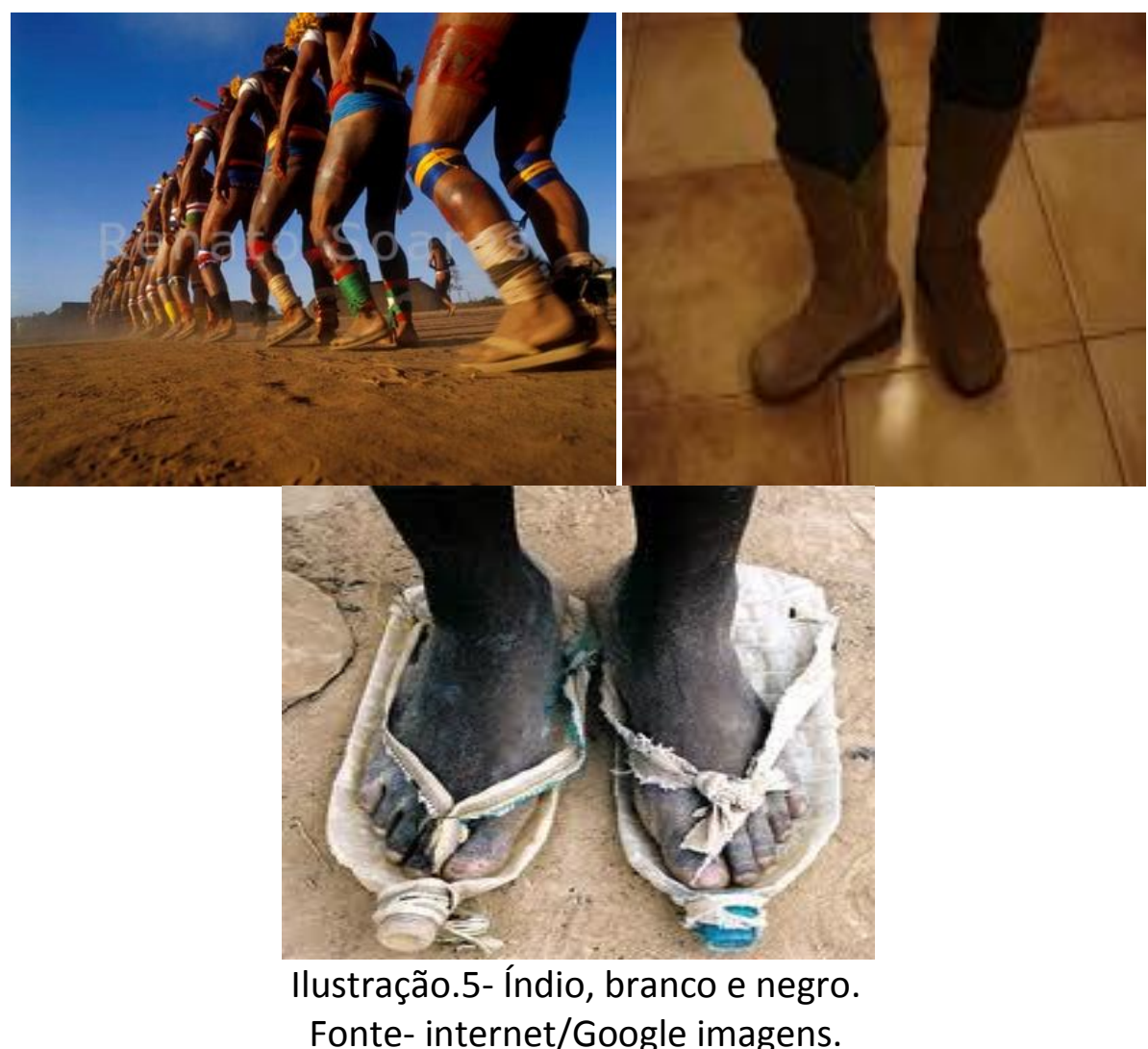

Ilustração. 6- O Brasil na cara.

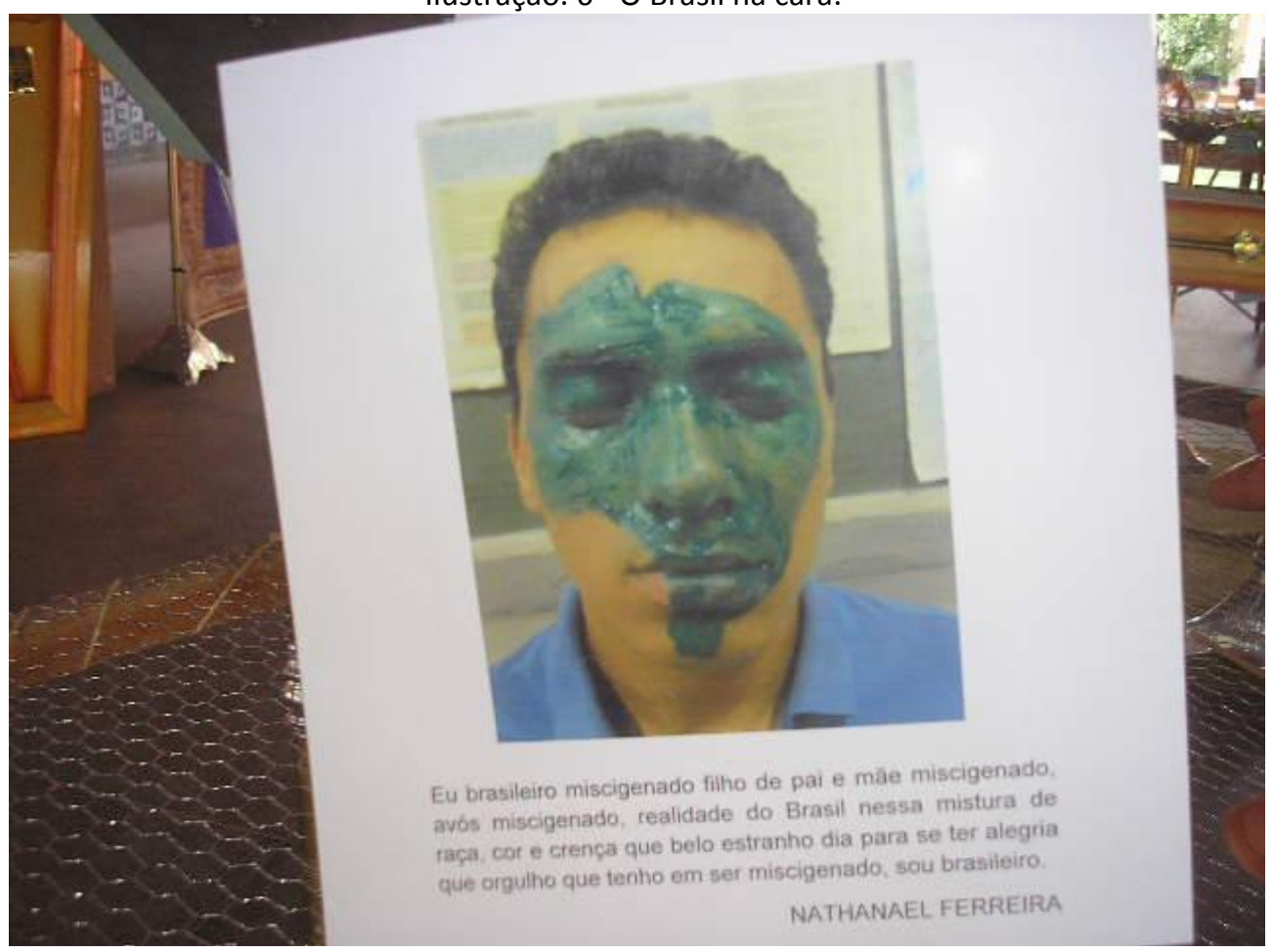

Fonte: Ribeiro, Emerson. Nov/2011. 


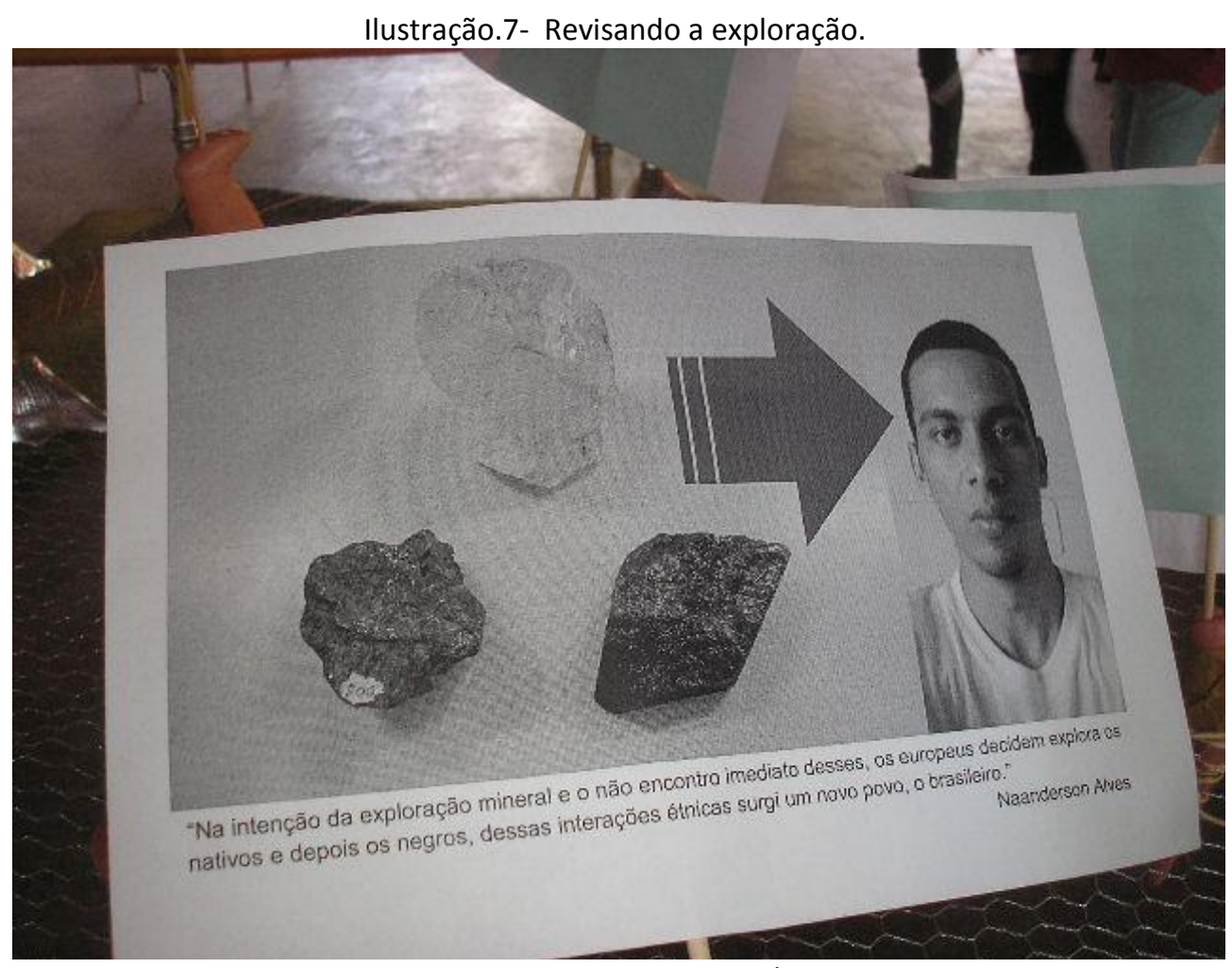

Fonte: Ribeiro, Emerson. Nov/2011.

\section{REMATE}

O tema avaliação nos últimos anos vem sendo tratado de longe na geografia, por ser um tema polêmico na escola e na Universidade, em função das mudanças que vem ocorrendo não só na concepção de aprendizagem como no sistema educacional ${ }^{4}$. Ainda hoje encontramos a avaliação com característica para aferir apenas a memorização, tratando de "fatos e datas históricos, cópia de mapa, etc." Baseado apenas na memorização e na repetição, base do ensino tradicional que custa a ser rompido pelo sistema educacional como um todo.

Nesse percurso exploramos a criatividade em geografia, sendo o resultado dessa prática manifestada em uma avaliação por instalações. Assim, as instalações diante do processo de avaliar se constrói pautada nos conceitos geográficos e na arte para que não fique aprisionada apenas a verbalização dos conceitos e termos, mas que alcance, pela mediação da arte signos e símbolos a

\footnotetext{
${ }^{4}$ A constatação dessa premissa pelo professor pesquisador se qualifica pela pouca apresentação de trabalhos sobre avaliação em congressos e encontros sobre práticas em geografia, não temos observados uma preocupação principalmente da geografia na universidade em discutir a avaliação. Esse tema não aparece nas mesas, em palestras em colóquios, também constato desde o ano 2000 como professor do ensino básico e coordenador que nas reuniões pedagógicas esse debate não foi colocado em pauta, quando raro apenas alguns comentários, por isso, essas observações.
} 
superação do entendimento dos fenômenos que fazem parte do processo de ensino aprendizagem materializando-se na prática social-espacial.

A instalação geográfica se dá na forma e conteúdo, ou seja, pelos conceitos apreendidos e estimulados pelo professor e o meio sócio- espacial. Essa instalação parte da proposta do professor em materializar o conteúdo ensinado aos alunos e para que a aprendizagem se realize pela avaliação construtiva. Esses conteúdos são abordados em sala de aula, tendo como suporte os livros didáticos, textos, vídeos entre outras práticas pedagógicas para a realização da compreensão dos conteúdos.

Acreditamos que a situação problema, inserida no processo de aprendizagem o qual tratamos que é a "a formação da população brasileira", passado os conteúdos que o abordam, e apresentando a segunda etapa desse trabalho que era de materializar em símbolos e signos esses conteúdos apreendidos pelos alunos, seguimos a terceira etapa que trata-se da pesquisa sobre a formação da população brasileira, tendo os seus significados materializados em símbolos e signos que representassem o trabalho em questão, essa pesquisa foi apresentada pelos alunos no que chamamos essa etapa de "Teia de Ideias" esses objetos pensados por eles serviriam a materialização da instalação, a qual foi exposta, sendo essa objeto de questionamento e aprendizado não só pelos alunos, mas pelos transeuntes.

É importante salientar que o trabalho apreende o conhecimento pelos símbolos e signos, onde os alunos são levados a exercitar o pensamento para além da lógica formal, e sim em busca de uma lógica dialética, em movimento, pois os símbolos e signos são atrelados por associação ao conteúdo estudado levando os alunos a um ensino e aprendizado significativo diante dos processos cognitivos.

Para a ruptura do exposto, acreditamos no processo pedagógico que abarca a criatividade em geografia e a metodologia por instalações geográficas que tratam do cotidiano no plano do vivido, enfocando o teórico e a prática alimentados pela pesquisa, a capacidade de observação, descrição e análise dos espaços e sua representação, o domínio de várias linguagens possíveis de serem usadas pela Geografia para que o aluno que esta em formação e será o formador domine os conhecimentos geográficos para a transformação da sala de aula.

Fica-nos um Fragmento: Para nos livrar do tédio, parafraseamos Fernando Pessoa: "cadáveres adiados que procriam". É preciso ressuscitar a universidade e a escola.

\section{REFERÊNCIAS}


AZZI, Sandra. Avaliação e progressão continuada. In: AZZI, S. (coord). Avaliação do desempenho e progressão continuada: projeto de capacitação de dirigentes. Belo Horizonte: SMED, out. 2001.

CALDEIRA, Anna M. Salgueiro. Avaliação e processo de ensino aprendizagem. Presença Pedagógica, Belo Horizonte, v. 3, p. 53-61, set./out. 1997.

Ressignificando a avaliação escolar. In: Comissão Permanente de Avaliação Institucional: UFMG-PAIUB. Belo Horizonte: PROGRAD/UFMG, 2000. p. 122-129 (Cadernos de Avaliação, 3).

CENTRO DE ARTE HÉLIO OITICICA, Hélio Oiticica: cor, imagem, poética. Rio de Janeiro: 2003, Catálogo de obras artísticas.

DEMO, Pedro. Teoria e prática da avaliação qualitativa. Temas do 2ำ Congresso Internacional sobre Avaliação na Educação. Curitiba, Paraná, 2004. p.156-166.

FERNANDES, Domingos. Para uma teoria da avaliação formativa. Universidade de Lisboa, Portugal. Revista Portuquesa de Educação, 2006, 19(2), pp. 21-50 2006, CIED - Universidade do Minho. www.scielo.oces.mctes.pt/pdf/rpe/v19n2a03.pdf

HADJI, Charles. Avaliação desmistificada. Porto Alegre, Artmed, 2001

LIBÂNEO, José Carlos. Didática. São Paulo: Cortez, 2004.

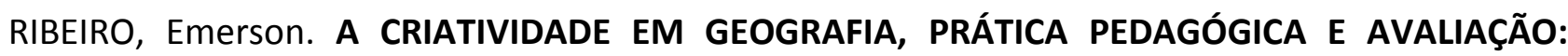
LANTERNAS GEOGRÁFICAS. Geosaberes, Fortaleza, v. 2, n. 4, p. 61-75, ago./ dez. 2011.

Avaliação ou pescaria? - por uma distinta possibilidade da aprendizagem em geografia na construção de instalações geográficas. Rev. Bras. Educ. Geog., Rio de Janeiro, v. 1, n. 2, p. 91-104, jul./dez., 2011.

PRÁTICAS PEDAGÓGICAS- O ENSINO GEOGRÁFICO POR INSTALAÇÕES. IX Seminário de Pós-Graduação em Geografia da UNESP Rio Claro, 3 a 5 de novembro de 2009. Acesso http://sites.google.com/site/seminarioposgeo/anais.

VYGOTSKY, LeV. S. PSICOLOGIA PEDAGÓGICA. 2 ED. TRAD. SÃO PAULO: MARTINS FONTES.2004. 
Artigo submetido em: 28/10/2013

Artigo aceito em: 22/04/2014 